\title{
Comparative studies on wood structure and microtensile properties between compression and opposite wood fibers of Chinese fir plantation
}

\author{
Zhu Li ${ }^{1,2}$, Tianyi Zhan ${ }^{3}$, Michaela Eder ${ }^{4}$, Jiali Jiang ${ }^{1}$, Jianxiong Lyu ${ }^{{ }^{*}}$ and Jinzhen Cao ${ }^{2}$
}

\begin{abstract}
The microtensile properties of mechanically isolated compression wood (CW) and opposite wood (OW) tracheids of Chinese fir (Cunninghamia lanceolata) were investigated and discussed with respect to their structure. Major differences in the tensile modulus and ultimate tensile stress were found between CW and OW fibers. Compared to OW, CW showed a larger cellulose microfibril angle, less cellulose content and probably more pits, resulting in lower tensile properties. These findings contribute to a further understanding of the structural-mechanical relationships of Chinese fir wood at the cell and cell wall level, and provide a scientific basis for better utilization of plantation softwood.
\end{abstract}

Keywords: Chinese fir, Tracheids, Mechanical properties, Compression wood, Opposite wood, Cellulose content, Microfibril angle

\section{Introduction}

Chinese fir (Cunninghamia lanceolata) is one of the main commercial plantation conifer tree species in China. Conifers consist mainly of axial tracheids, serving for support and for transport of water and dissolved minerals. Their anatomical structure, chemical composition and the spatial arrangement of polymers in the wood cell wall determines their mechanical properties. Thus, information about the micromechanics of single tracheids can be helpful to deepen our understanding of the structural-mechanical relationships of wood at the cell and cell wall level.

Considerable differences in the micro- and ultrastructure of wood tracheids have been found between compression wood (CW), opposite wood (OW), normal wood or juvenile wood [1-4]. Compared to normal

\footnotetext{
*Correspondence: jianxiong@caf.ac.cn

${ }^{1}$ Research Institute of Wood Industry of Chinese Academy of Forestry, Hunan Collaborative Innovation Center for Effective Utilizing of Wood \& Bamboo Resources, Beijing 100091, China

Full list of author information is available at the end of the article
}

wood, CW shows the largest differences: an absence of $\mathrm{S}_{3}$ layer of the shorter tracheids, with helical cavities and a large cellulose microfibril angle (MFA) in an $\mathrm{S}_{2}$ layer of the cell wall. In terms of the chemical composition, the lignin content is higher and the cellulose content is lower with a lower degree of crystallinity $[1,2,5-8]$. It is well known that the mechanical properties of plant fibers depend on the anatomical structure [9], the chemical composition [10] and the MFA [11]. Plant fibers with a higher MFA have a smaller modulus of elasticity, higher flexibility but also a reduced ultimate tensile stress compared to fibers with lower MFAs [11-14]. The MFA is probably the most important structural parameter on the cell wall scale influencing the mechanical performance of plant fibers in their axial direction. At the level of the cell, pits of various forms and structural defects effect the tensile properties $[15,16]$ as well as cell wall thicknesses and cell geometries $[9,11]$. Observed differences in the ultimate tensile stress between earlywood, transition wood and latewood with very similar MFAs could be related to 
tension buckling which primarily occurs in thin-walled earlywood fibers [13].

Tensile tests on adult single spruce fibers combined with Raman microscopy have revealed wavenumber shifts of peaks assigned to cellulose; while no wavenumber shifts for lignin-assigned peaks were detected upon mechanical loading [17]. In other words, the cellulose molecules take up the main load in these fibers with presumably small MFA and are responsible for the mechanical strength and elasticity under static stretching $[18,19]$. In a recent study both normal wood (small MFA) and compression wood slices (large MFA) were subjected to static and dynamic loading conditions while the molecular deformations were studied by polarized Fourier transform infrared spectroscopy. Static loading showed molecular deformation of cellulose only, while lignin remained without any molecular deformation [19]. However, in dynamic experiments changes in lignin were observed as well as differences in lignin of compression and normal wood. Furthermore, the authors found that molecular deformations of cellulose were larger in normal wood due to the smaller MFA [19]. In general, it is difficult to study the role of lignin during tensile loading, because changes in lignin content typically occur together with changes in MFA. Recently, Özparpucu et al. [20] found on genetically modified poplar slices with similar MFAs but different lignin contents, that lignin contributed to the axial stiffness by increasing the shear stiffness of the cell wall matrix; and the influence of lignin content on axial stiffness may gradually increase as a function of the MFA. In addition to these studies, effects of chemical treatments on plant fiber mechanics were studied experimentally [10, 21]. Back to the single-fiber level, Zhang et al. [10] investigated the effects of chemical components on the tensile strength and modulus of single fibers from Chinese fir. They found that chemical treatments reduced tensile strength and modulus, except for the tensile strength of completely delignified wood fibers; the removal of hemicellulose caused more effects on the mechanical properties of cell walls than the lignin removal. Similar results exist for single bamboo fibers [21].

While datasets about native normal wood and severe compression wood fibers exist, to the best of our knowledge nothing is known about the tensile properties of $\mathrm{CW}$ and $\mathrm{OW}$ fibers despite their frequent occurrence in stems. The objective of this present study was to investigate the mechanical properties of single fibers in $\mathrm{CW}$ and OW from Chinese fir stem wood in microtensile tests at laboratory conditions $\left(25{ }^{\circ} \mathrm{C}\right.$ and $50 \%$ relative humidity). Microstructure, MFA as well as chemical composition were determined and the mechanical properties were graphically displayed with existing literature data. A deep understanding of tracheid properties is necessary for better scientific cultivation and utilization of fast-growing softwoods.

\section{Materials and methods Fibers preparation}

Wood blocks with similar sizes were cut from the outer parts of $\mathrm{CW}$ and $\mathrm{OW}$ of fast-grown plantation Chinese fir (Cunninghamia lanceolata) stems at a height of $1.3 \mathrm{~m}$. All wood blocks were soaked in distilled water. Thin longitudinal-tangential tissue slices $(150 \mu \mathrm{m})$ were cut from the transition wood between earlywood and latewood with a rotary microtome (RM2255; LEICA, Bensheim, Germany). In order to retain the single fibers (tracheids) in their natural state, the mechanical isolation procedure was performed using very fine tweezers under a light microscope [22]. After isolation the wet fibers were dried under glass sheets to avoid twisting [23].

\section{X-ray diffraction measured and chemical analysis}

A Philips X-ray diffraction system (X'pert Pro, PANalytical B.V., Almelo, NL) was used to evaluate the MFA of the different slices from CW and OW (11th-13th growth ring). The samples were attached to the sample holder by a double-sided adhesive tape. Six samples were obtained for each wood type. The calculation of the MFAs was performed according to the procedure described by $\mathrm{Li}$ et al. [24]. The samples of the X-ray analysis were used for chemical analysis afterwards. The content of cellulose and lignin was analyzed in accordance with the GB/T 744-2004 [25] and GB/T 747-2003 [26] standards, respectively.

\section{Microtensile tests}

The mechanical properties of the single fibers were tested in tension by using a microtensile testing device equipped with a $500 \mathrm{mN}$ maximum capacity load cell, as described in detail in [27]. The air-dried single tracheids were glued onto $200-\mu \mathrm{m}$-thick polyester frames under a light microscope by using cyanoacrylate glue (Loctite 454). Prior to the tensile test and after glue-hardening, the test spans of the fibers were measured. The foliar frames carrying the individual cells were fixed by a pinhole assembly and were strained with a test speed of $0.5 \mu \mathrm{m} / \mathrm{s}$. All the tensile testing was carried out at $25{ }^{\circ} \mathrm{C}$ and $50 \%$ relative humidity.

To calculate the ultimate stress and tensile stiffness of the fibers, both the cell and cell wall cross-sectional areas were determined according to the method described previously [28]. Typically, one part of the broken fibers were dipped into polyethylene glycol 2000 followed by sectioning with razor blades under a stereo-microscope and rinsing with warm water. The sectioned surfaces were 
Table 1 The microfibril angle (MFA) and relative content of cellulose and lignin for compression wood (CW) and opposite wood (OW). Values in parenthesis are the coefficients of variation (\%)

\begin{tabular}{llll}
\hline Samples & MFA $\left({ }^{\circ}\right)$ & Cellulose (\%) & Lignin (\%) \\
\hline CW & $25.1(7.79)$ & $42.64(1.18)$ & $36.43(0.83)$ \\
OW & $11.5(2.43)$ & $46.89(0.43)$ & $32.81(0.75)$ \\
\hline
\end{tabular}

then observed using an environmental scanning electron microscope (ESEM; FEI Quanta 600) under low vacuum conditions to obtain images for area calculation using the software ImageJ. In total, ten successful measurements were performed for both CW and OW fibers.

\section{Results and discussion}

\section{Chemical composition and structural properties}

The values of MFA and relative content of cellulose and lignin for $\mathrm{CW}$ and $\mathrm{OW}$ from Chinese fir wood are presented in Table 1. The mean MFA values in the $S_{2}$ layer were $25.1^{\circ} \pm 2.0^{\circ}$ and $11.5^{\circ} \pm 0.3^{\circ}$ for $\mathrm{CW}$ and $\mathrm{OW}$, respectively. The low MFAs of OW are in a similar range compared to the normal heartwood of six Chinese fir clones which ranged from $10.47^{\circ}$ to $13.18^{\circ}$ [29]. CW showed a higher MFA than OW, which is associated with environmental stimuli such as slope, winds, or other external forces $[30,31]$. As shown in Table 1, the relative content of cellulose and lignin in CW was $42.64 \%$ and $36.43 \%$, respectively; and those in OW was $46.89 \%$ and $32.81 \%$, respectively. Clearly, compared to OW, CW had a higher lignin content and a lower cellulose content. The observed differences in lignin content between OW and CW are similar to those reported by Zhang et al. [32] for Chinese fir and Shirai et al. [33] for Gingko (38-39\% lignin content of CW and 34-37\% for OW). Based on the values of MFAs and the chemical composition analysis, the region chosen featured the mild type of $\mathrm{CW}$ from Chinese fir wood.

\section{Tensile properties of single wood fibers}

Exemplary stress-strain curves of CW and OW fibers from Chinese fir are shown in Fig. 1. For the individual fibers, the shape of the stress-strain curve appeared to be linear during the initial phase of the test, which has been repeatedly observed in some previous studies $[10,11$, 22]. The failure strain of $C W$ tracheids was slightly larger than that of OW tracheids, an effect that can be assigned to the larger MFA [11, 12].

During the tensile tests, the average maximum load was $61 \mathrm{mN}$ for $\mathrm{CW}$ fibers and $107 \mathrm{mN}$ for OW fibers. Since the differences in cross-sectional geometries can be quite large between single wood fibers, stresses were calculated on the basis of cell and cell wall cross-sections

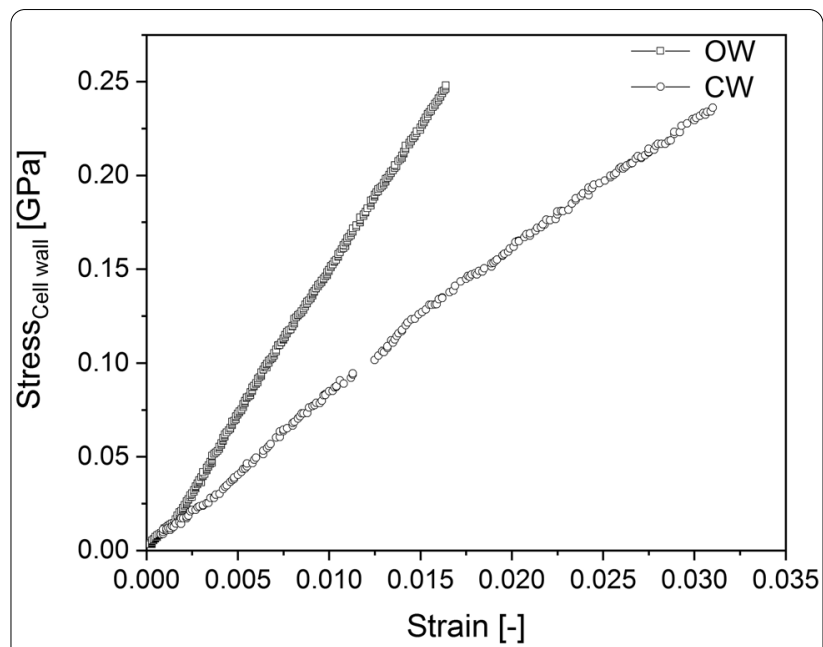

Fig. 1 The typical stress-strain curves for wood single fibers of OW and $C W$

instead of analyzing forces. Furthermore, this allows a thorough comparison with literature data. Based on the stress strain diagrams tensile stiffness and ultimate tensile stress were determined (Fig. 2a, b), we found significant differences (Mann-Whitney test, statistically significant at the 0.05 level, Origin Pro 2020) between the tensile properties of $\mathrm{OW}$ and $\mathrm{CW}$, except for the tensile stiffness when calculated on the basis of the cell crosssections. Naturally, the tensile properties calculated on the cell cross-sections (box plots in the right corners of Fig. 2a, b) were lower than those calculated on cell wall cross-sections since the empty lumen does not contribute to tensile stiffness and strength. This is also a reason why the differences between the two-fiber groups appear more pronounced for the cell wall data.

The OW tracheids calculated on the cell wall cross-sections had the highest tensile modulus and ultimate tensile stress of $14.5 \mathrm{GPa}$ and $314 \mathrm{MPa}$, respectively, which was more than 1.5 times higher than the tensile modulus and ultimate stress of CW tracheids (8.17 GPa and $196 \mathrm{MPa}$, calculated on the cell wall cross-sections). The lower mechanical properties of $\mathrm{CW}$ fibers can be explained by the larger MFA ( $25.1^{\circ}$ for $\mathrm{CW}$ and $11.5^{\circ}$ for OW) which have been shown to decrease with increasing MFA [1114]. Unfortunately, only few literature data exists for single-fiber properties of Chinese fir. However, Yu et al. [11] determined the average tensile modulus of $17.6 \mathrm{GPa}$ and ultimate tensile stress of $770 \mathrm{MPa}$ for chemically isolated Chinese fir sapwood fibers with a MFA of $\sim 12^{\circ}$.

To get a better idea about these differences in wood fiber properties, the present mechanical data were plotted versus the MFA together with literature data-all calculated for cell wall cross-sections (Fig. 3a, b). The 

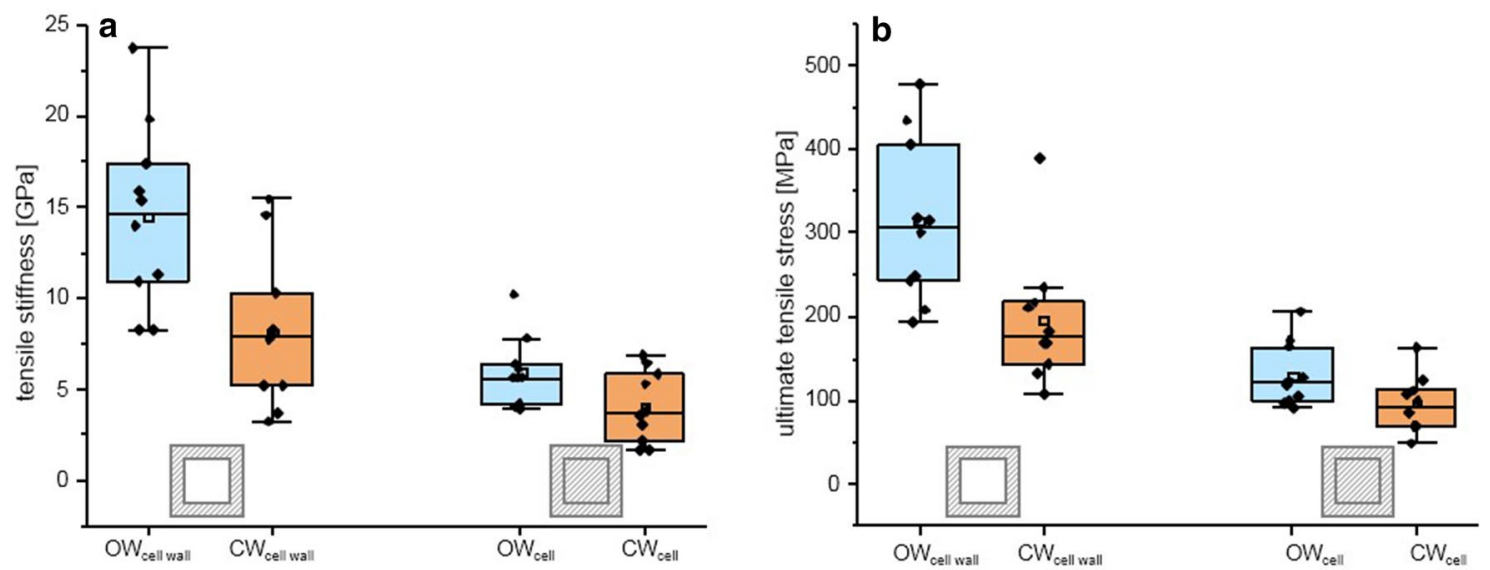

Fig. 2 Mechanical properties of OW and CW fibers of Chinese fir stem. Tensile stiffness (a) and ultimate tensile stress (b) were calculated both on the cell wall and cell cross-sections (left cartoon in the diagrams shows shaded cell wall and right cartoon cell cross-sections)
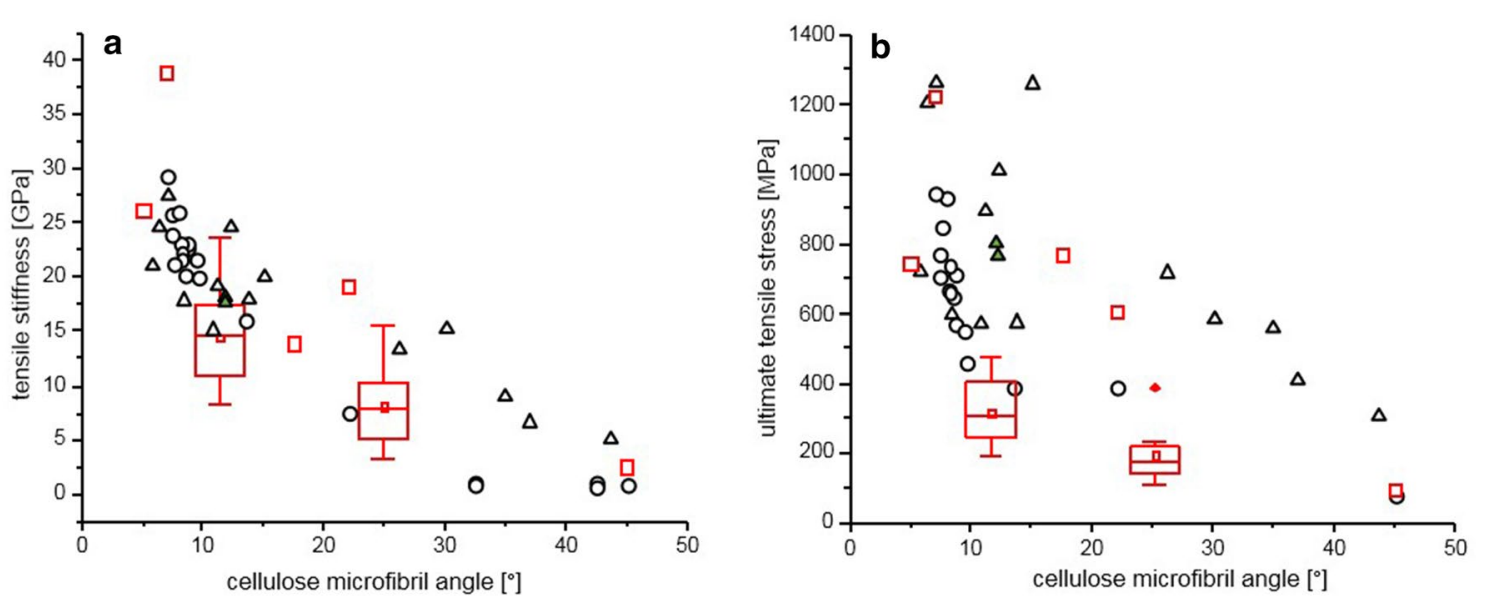

Fig. 3 Mechanical properties vs MFA — comparison with data from literature. Each datapoint represents multiple single fibers tensile tests. Triangles: chemically isolated fibers, green triangles newly added datapoints, tested under laboratory conditions. Circles: mechanically isolated and tested in wet condition. Rectangles: mechanically isolated, tested under laboratory conditions. Box plots: OW and CW single fibers data. Red literature data points and new red boxplot data were tested under similar conditions. Data from literature were taken from [9, 11, 35-38]

majority of the plotted data has been published in a similar diagram before [34] and was supplemented by more recent data on Masson pine and Chines fir [11]. The datasets of Fig. 3a show a clear relationship between the tensile stiffness and MFA, both for chemically isolated fibers tested under laboratory conditions (triangles), mechanically isolated fibers tested in the wet state (circles) and mechanically isolated fibers, tested under laboratory conditions (red rectangles). Data displayed in red were created under similar test conditions as the present data (box plots). Whereas larger datasets exist for both wet tested mechanically isolated fibers and for chemically isolated fibers, data about dry-tested mechanically isolated fibers with known MFA is scarce. However, for the series of chemically isolated fibers (triangles) the newly added data points for Chinese fir and Masson pine (green filled) are in the same range as the other triangles. This suggests that differences in tensile behavior between tree species are small-at least after chemical isolation. The two circles at $\sim 33^{\circ}$ MFA (Ginkgo and Juniperus) suggest that species-related differences could also be small for mechanically isolated fibers. However, this is just speculative.

Despite the lack of a large literature datasets, CW fibers from Chinese fir fit well into the tensile stiffness diagram. The data for OW are slightly lower than comparable 

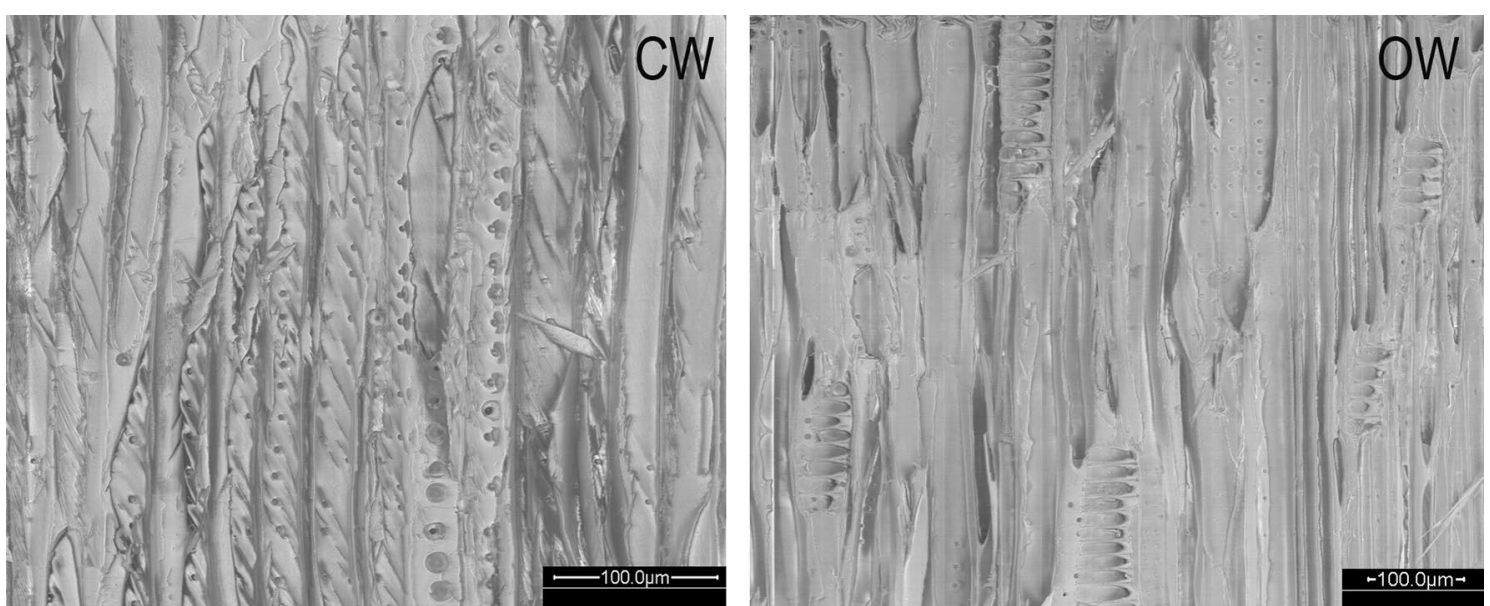

Fig. 4 Scanning electron micrographs of the distribution and size of pits on radial sections of CW and OW from Chinese fir wood

data from literature. In terms of ultimate tensile stress (Fig. 3b), literature data are broadly scattered. Reasons are that experimenters cannot pre-determine a site of fracture by tapering, etc., which means that the fibers will always break at sites with high stress concentrations close to the clamps or at areas along the fibers with high stress concentrations such as structural defects or pits. Furthermore, sample geometries such as cell wall thickness play a role concerning the fracture mode. This can be seen well in the diagram (Fig. 3b) for MFAs with a large number of datapoints (around $10^{\circ}$ ), regardless of the isolation procedures. However, ultimate tensile stresses of CW (and also of OW, but to a lesser extent) are lower than all literature data for a comparable MFA. It can only be speculated that heavily pitted CW tracheids, as shown in Fig. 4, or helical cavities promote early fracture. The reasons for the early fracture of OW tracheids remain unclear at this stage.

Another reason for the observed lower values of Chinese fir fibers could be differences in chemical composition. Based on already published data and the presented data, no conclusions can be made since numerous protocols for chemical analyses exist and the results are not directly comparable. However, our results suggest that single-fiber tests of wood of various species with differences chemical composition could contribute to answer the long-standing question of the role of wood polymers for cell wall mechanics of native wood. Each tree consists of wood with a wide range of MFAs. By comparing fibers with the same MFA and similar geometries but different chemical composition it might be possible to gain a much deeper understanding.

\section{Conclusion}

The structural characterization, chemical composition, and microtensile properties of the single tracheids between CW and OW from Chinese fir wood in fastgrowth plantation were tested and compared. The tensile modulus and ultimate tensile stress of $\mathrm{CW}$ tracheids were lower than those of OW due to the larger MFA but the relatively lower cellulose content, more pits and the missing S3 layer might also play a role. A comparison with literature data showed slightly lower mechanical values than expected. These results can contribute to a further understanding of the structural-mechanical relationships of Chinese fir wood at the cell wall level, and provide a scientific basis for better utilization of plantation softwood.

\section{Abbreviations}

CW: Compression wood; OW: Opposite wood; MFA: Microfibril angle.

\section{Acknowledgements}

The authors are grateful for the financial support from the National Natural Science Foundation of China (No. 31971591). Gratitude goes to Liang Zhou (Anhui Agricultural University, China) for providing the compression wood of Chinese fir wood.

\section{Authors' contributions}

$\mathrm{ZL}, \mathrm{ME}, \mathrm{JL}$ and JC conceived and designed the experiments; ZL and JJ wrote the manuscript; ZL and TZ performed the experiments and analyzed data. All authors read and approved the final manuscript.

\section{Funding}

This research was sponsored by the National Natural Science Foundation of China (No. 31971591).

\section{Availability of data and materials}

The datasets used and/or analyzed during the current study are available from the corresponding author on reasonable request. 


\section{Competing interests}

The authors declare that they have no competing interests.

\section{Author details}

${ }^{1}$ Research Institute of Wood Industry of Chinese Academy of Forestry, Hunan Collaborative Innovation Center for Effective Utilizing of Wood \& Bamboo Resources, Beijing 100091, China. ${ }^{2}$ College of Materials Science and Technology, Beijing Forestry University, Beijing 100083, China. ${ }^{3}$ College of Materials Science and Engineering, Nanjing Forestry University, Nanjing 210037, China. ${ }^{4}$ Department of Biomaterials, Max-Planck-Institute of Colloids and Interfaces, Wissenschaftspark Golm, Am Mühlenberg 1, 14476 Potsdam, Germany.

Received: 12 October 2020 Accepted: 1 February 2021

Published online: 09 February 2021

\section{References}

1. Donaldson LA, Grace J, Downes GM (2004) Within-tree variation in anatomical properties of compression wood in radiate pine. IAWA J 25:253-271

2. Yeh TF, Goldfarb B, Chang HM, Peszlen I, Braun JL, Kadla JF (2005) Comparison of morphological and chemical properties between juvenile wood and compression wood of loblolly pine. Holzforschung 59:669-674

3. Tarmian A, Azadfallah M (2009) Variation of cell features and chemical composition in spruce consisting of opposite, normal, and compression wood. BioResources 4:194-204

4. Purusatama BD, Kim NH (2018) Qualitative anatomical characteristics of compression wood, lateral wood, and opposite wood in the stem wood of Ginkgo biloba L. BioResources 13:8076-8088

5. Timell TE (1986) Compression wood in gymnosperms. Springer, Heidelberg

6. Fagerstedt KV, Mellerowicz E, Gorshkova T, Ruel K, Joseleau JP (2014) Cell wall polymers in reaction wood. The biology of reaction wood. Springer, Berlin

7. Peng H, Salmén L, Stevanic JS, Lu JX (2019) Structural organization of the cell wall polymers in compression wood as revealed by FTIR microspectroscopy. Planta 250:163-171

8. Purusatama BD, Choi JK, Lee SH, Kim NH (2020) Microfibril angle, crystalline characteristics, and chemical compounds of reaction wood in stem wood of Pinus densiflora. Wood Sci Technol 54:123-137

9. Eder M, Jungnikl K, Burgert I (2009) A close-up view of wood structure and properties across a growth ring of Norway spruce (Picea abies [L.] Karst.). Trees 23:79-84

10. Zhang SY, Wang CG, Fei BH, Yu Y, Cheng HT, Tian GL (2013) Mechanical function of lignin and hemicelluloses in wood cell wall revealed with microtension of single wood fiber. BioResources 8:2376-2385

11. Yu Y, Wang HK, Lu F, Tian GL, Lin JG (2014) Bamboo fibers for composite applications: a mechanical and morphological investigation. J Mater Sci 49:2559-2566

12. Reiterer A, Lichtenegger H, Tschegg S, Fratzl P (1999) Experimental evidence for a mechanical function of the cellulose microfibril angle in wood cell walls. Philos Mag 79:2173-2184

13. Eder M, Stanzl-Tschegg SE, Burgert I (2008) The fracture behaviour of single wood fibres is governed by geometrical constraints: in situ ESEM studies on three fibre types. Wood Sci Technol 42:67-689

14. Wang D, Lin LY, Fu F (2020) Deformation mechanisms of wood cell walls under tensile loading: a comparative study of compression wood (CW) and normal wood (NW). Cellulose 27:4161-4172

15. Sedighi-Gilani M, Navi P (2007) Experimental observations and micromechanical modeling of successive-damaging phenomenon in wood cells' tensile behavior. Wood Sci Technol 41:69-85

16. Sirviö J, Kärnlampi P (1998) Pits as natural irregularities in softwood fibers. Wood Fiber Sci 30:27-39

17. Gierlinger N, Schwanninger M, Reinecke A, Burgert I (2006) Molecular changes during tensile deformation of single wood fibers followed by Raman microscopy. Biomacromol 7:2077-2081
18. Salmén L, Bergström E (2009) Cellulose structural arrangement in relation to spectral changes in tensile loading FTIR. Cellulose 16:975-982

19. Peng H, Salmén L, Jiang JL, Lu JX (2020) Contribution of lignin to the stress transfer in compression wood viewed by tensile FTIR loading. Holzforschung 74:459-467

20. Özparpucu M, Gierlinger N, Cesarino I, Burgert I, Boerjan W, Rüggeberg M (2019) Significant influence of lignin on axial elastic modulus of poplar wood at low microfibril angles under wet conditions. J Exp Bot 70:4039-4047

21. Yang X, Wang K, Tian G, Yang S (2018) Evaluation of chemical treatments to tensile properties of cellulosic bamboo fibers. Eur J Wood Prod 76:1303-1310

22. Burgert I, Keckes J, Frühmann K, Fratzl P, Tschegg SE (2002) A comparison of two techniques for wood fibre isolation-evaluation by tensile tests of single fibres with different microfibril angle. Plant Biol 4:9-12

23. Burgert I, Frühmann K, Keckes J, Fratzl P, Stanzl-Tschegg S (2005) Properties of chemically and mechanically isolated fibres of spruce (Picea abies [L.] Karst.). Part 2: twisting phenomena. Holzforschung 59:247-251

24. Li J, Zhang XX, Zhu JW, Yu Y, Wang HK (2020) Structural, chemical, and multi-scale mechanical characterization of waste windmill palm fiber (Trachycarpus fortunei). J Wood Sci 66:8-16

25. GB/T 744-2004 (2004) Pulps-determination of alkali resistance. Chinese National Standardization Management Committee, Beijing

26. GB/T 747-2003 (2003) Pulps-determination of acid-insoluble lignin. Chinese National Standardization Management Committee, Beijing

27. Burgert I, Frühmann K, Keckes J, Fratzl P, Stanzl-Tschegg SE (2003) Microtensile testing of wood fibers combined with video extensometry for efficient strain detection. Holzforschung 57:661-664

28. Burgert I, Eder M, Frühmann K, Keckes J, Fratzl P, Stanzl-Tschegg S (2005) Properties of chemically and mechanically isolated fibres of spruce (Picea abies [L.] Karst.). Part 3: mechanical characterisation. Holzforschung 59:354-357

29. Sun HY (2019) Wood mechanical properties and their correlation with microstructural of Chinese fir clones. Chinese academy of Forestry, Beijing

30. Timell TE (1983) Origin and evolution of compression wood. Holzforschung 37:1-10

31. Barry G, John B, Pekka S, Joseph G (2014) The biology of reaction wood. Springer, Heidelberg

32. Zhang SL, Liu JJ, Lou XZ, Liu Y, Tong ZK, Huang HH (2015) Morphological characteristics of cells and main metabolic components in xylem of Cunninghamia lanceolata compression wood. J Beijing Forest Univ 37:126-133

33. Shirai T, Yamamoto H, Matsuo M, Inatsugu M, Yoshida M, Sato S, Sujan KC, Suzuki Y, Toyoshima I, Yamashita N (2016) Negative gravitropism of Ginkgo biloba: growth stress and reaction wood formation. Holzforschung 70:267-274

34. Eder M, Arnould O, Dunlop JWC, Hornatowska J, Salmén L (2012) Experimental micromechanical characterisation of wood cell walls. Wood Sci Technol 47:163-182

35. Burgert I, Fruhmann K, Keckes J, Fratzl P, Stanzl-Tschegg S (2004) Structure-function-relationships of four compression wood types: micromechanical properties at the tissue and fibre level. Trees 18:480-485

36. Keunecke D, Eder M, Burgert I, Niemz P (2008) Micromechanical properties of common yew (Taxus baccata) and Norway spruce (Picea abies) transition wood fibers subjected to longitudinal tension. J Wood SCi 54:420-422

37. Mott L, Groom L, Shaler S (2002) Mechanical properties of individual southern pine fibers. Part II. Comparison of earlywood and latewood fibers with respect to tree height and juvenility. Wood Fiber Sci 34:221-237

38. Wang G, Yu Y, Shi SQ, Wang JW, Cao SP, Cheng HT (2011) Microtension test method for measuring tensile properties of individual cellulosic fibers. Wood Fiber Sci 43:251-261

\section{Publisher's Note}

Springer Nature remains neutral with regard to jurisdictional claims in published maps and institutional affiliations. 